2870

日本機械学会論文集 $(\mathrm{C}$ 編 $)$

76 巻 771 号 (2010-11)

論文 No. 10-0187

\title{
音響フィルエフェクト負荷時の宇宙機振動応答に関する簡易計算法*
}

\author{
熊 谷尚 孝*1, 安藤 成 将*2, 施 勤 忠*2 \\ 土橋将 弘*3, 森 村 浩 明*4, 萩原一 郎*5
}

\section{Simplified Spacecraft Vibration Analysis Subjected to Acoustic Fill Effect}

\author{
Naotaka KUMAGAI, Shigemasa ANDO, Qinzhong SHI, \\ Masahiro TSUCHIHASHI, Hiroaki MORIMURA and Ichiro HAGIWARA*6 \\ ${ }^{* 6}$ Graduate School of Mechanical Science and Mechanical Engineering, Tokyo Institute of Technology, \\ 2-12-1 O-okayama, Meguro-ku, Tokyo, 152-8552 Japan
}

\begin{abstract}
Spacecraft inside a fairing experiences severe high-level random acoustic loads during its launch. To confirm that the spacecraft structures and equipment withstand the launch environment, ground acoustic test is performed in the process of design. Spacecraft is exposed to a diffuse sound field in a large reverberant room during ground acoustic test. On the other hand, spacecraft, especially that has a narrow clearance between spacecraft exterior panel and fairing wall, is exposed to the standing wave sound field, which is called 'Fill Effect', instde a fairing during launch. Fill effect has been identified for these few decades, but there have been few reports to discuss the vibration response of a spacecraft induced by the fill effect. In this paper, the simplified approach is proposed to compare the vibration response of a spacecraft induced by standing wave sound field with the one by diffuse sound field. This approach can be dedicated to the desigh of a spacecraft which may be exposed to severe fill effect. One analysis example of a plate structure under these two sound fields is shown.
\end{abstract}

Key Words: Space Engineering, Fairing, Fill Effect, Spacecraft, Diffuse Sound Field, Standing Wave Field

\section{1. 緒}

人工衛星等の宇宙機は，ロケット先端部のフェアリ ングと呼ばれるカバーに格納されて宇宙空間に輸送 される. 宇宙機構体は，ロケット打上時のエンジン 燃焼や流体加振により生じる音響（130dB 以上）に晒 され，その音響によりランダム振動が励起される. このため，宇宙機の開発においては，宇宙機を反響 室と呼ばれる拡散音場を実現出来る音響試験室に設

* 原稿受付 2010 年 3 月 17 日.

*1 東京工業大学大学院理工学研究科機械物理工学專攻 (念 1528552 東京都目黑区大岡山 2-12-1).

*2 正員, (独)宇笛航空研究開発機構( 305-8505 つく以゙市千 現 2-1-1).

*3 (独) 宇笛航空研究開発機構.

*4 正員, 東京工策大学大学院イノベーション研究センター。

*5 正員, フェロー, 東京工業大学大学院理工学研究科機械物理 工学専攻.

E-mail : hagiwara.j.aa@m.titech.ac.jp
置し，ロケット側より規定される音圧を印加する音 響試験を行い，宇宙機の耐音響環境性を確認する.

宇宙機がフェアリング内に搭載され，打ち上げられ る際には，フェアリング壁と宇宙機構体間の狭い隙 間において，局所的に音圧が上昇するフィルエフェ クト(1)(4) と呼ばれる現象が確認されている。このフ イルエフェクトは, 狭い吵間の局所的な定在波音場 が原因であり ${ }^{(3)}{ }^{(4)}$ ，多くの場合，数十 $\mathrm{Hz}$ から $200 \mathrm{~Hz}$ 付近で顕著である.

宇宙機の音響試験では，フィルエフェクトによる 音圧の上昇分を加味したレベルで拡散音場による音 響試験を実施することが推奨されている例もある(5). しかし，これまでのフィルエフェクトに関する研究 では，音圧の上昇量予測に焦点があてられており， 宇宙機構造の振動応答への影響については, 殆ど検 討されていないのが現状である.フィルエフェクト の顕著な周波数帯域では, 宇宙機構造の全機振動モ 一ドよりも，宇宙機構体を構成する平板パネル，太 
陽電池パネル，アンテナ等の局所的な低次曲げ振動 モードが特に重要である.

これらの低次曲げ振動について，宇宙機の検証過 程で行われる音響試験での拡散音場負荷と, フライ 卜時の定在波音場負荷における，振動応答の比較評 価を行う必要がある。また，フィルエフェクトによ る定在波音場は，音場開口部の境界条件や間隔によ って異なるため, 設計上は, フィルエフェクトによ る構造物応答の最大值が必要となる.

そこで，本論文では，拡散音場と定在波音場の平板 応答を比較検討するための簡易計算法を提案する．定 在波音場負荷時の応答の最大值を求めるため, 音圧分 布式に乱数を用いて，モンテカルロ法を適用する. 拡 散音場負荷時と定在波音場負荷時の構造振動応答の比 較結果の一例として, 提案する簡易計算法の矩形平板 八の適用例を示寸。

\section{2. フィルエフェクト}

フェアリング内部では, 衛星の体積が小さいと, 概 权一様な拡散音場に近い音場が形成されるが, 衛星 とフェアリングのクリアランスが小さい大型衛星の 場合は, この狭い空間でフィルエフェクトが発生し, 局所的に大きな音圧が発生する. 筆者らが, フェア リング内に宇宙機を搭載し音響試験を行い，フェア リング内部音圧を計測した結果を図 1 に示す.隙間の 小さい狭い空間(Zone C)において, $300 \mathrm{~Hz}$ 以下の低周 波で音圧レベルが上昇していることが分かる.

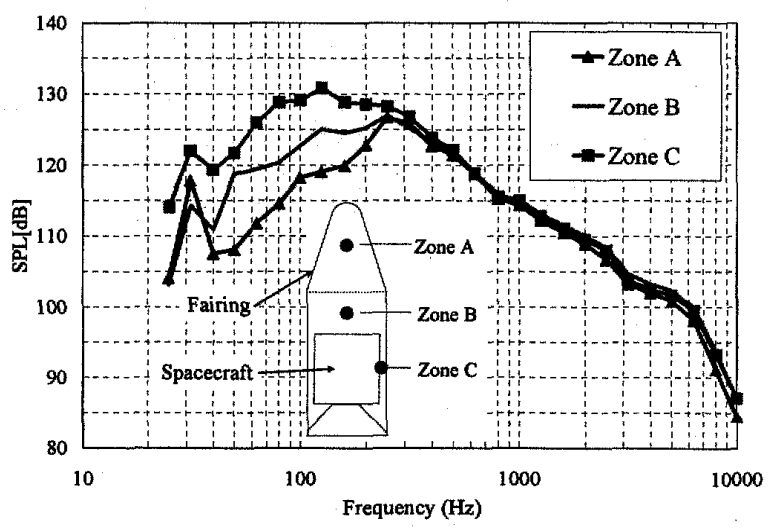

Fig.1 Sound pressure level distribution inside a fairing

小金井らは，宇宙機構体及びフェアリング壁をそれ ぞれ二枚の平板で模擬し，それらに拡散音場を負荷 するモデルを境界要素法で解析し，フィルエフェク トの原因は，狭い音響空間における定在波音場であ ることを示した ${ }^{(3)(4)}$.また，この定在波音響モードは， 平板の面内方向にのみ音圧が変化するモードである ことを示した. 本論文では, フィルエフェクト発生
時の外力として，この音場を考慮し，宇宙機構体は 平板でモデル化する.

\section{3. 拡散音場及び定在波音場加振時の平板振動応答}

本章では，拡散音場と定在波音場が負荷された場合 の平板の振動応答をそれぞれ導出する. 図 2 に示すよ うに無限板バッフルを持つ矩形平板が, 音圧 $p(\mathbf{x}, t)$ の外力を受けている問題を考える. 平板の法線方向 に $z$ 軸, 平板の辺に沿って $x, y$ 軸をとり, 平板の寸法 は $L_{x}, L_{y}$ であり， $A$ は平板の領域である. $\mathrm{x}$ は平板上 の点を表す。

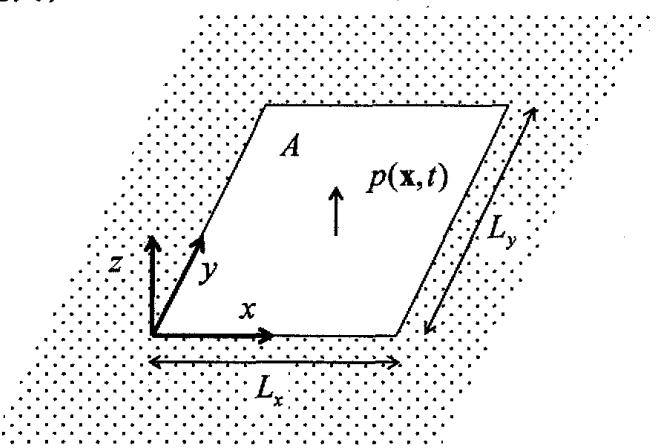

Fig. 2 Rectangular plate excited by pressure

平板の運動方程式は次式で書ける.

$$
D \nabla^{4}+\mu \ddot{w}=p(\mathbf{x}, t)
$$

ここで， $D, w, \mu$ はそれぞれ，平板の曲け剛性， $z$ 方 向変位, 面密度である. 平板の曲げ剛性は, $E, h, v$ をそれぞれ平板のヤング率，板厚，ポアソン比とし て, $D=E h^{3} /\left\{12\left(1-v^{2}\right)\right\}$ である. モード解析により， 式(1)をモード座標に展開すると, $r$ 次振動モードの運 動方程式は次式となる。

$$
\begin{aligned}
& \ddot{q}_{r}+2 \zeta_{r} \omega_{r} \dot{q}_{r}+\omega_{r}^{2} q_{r}=\frac{p_{r}}{\Lambda_{r}} \\
& \Lambda_{r}=\int_{A} \mu \phi_{r}^{2}(\mathbf{x}) d \mathbf{x} \\
& p_{r}(t)=\int_{A} \phi_{r}(\mathbf{x}) p(\mathbf{x}, t) d \mathbf{x}
\end{aligned}
$$

ここに， $q_{r}$ はモード変位， $\omega_{r}$ は固有角振動数， $\zeta_{r}$ は 減衰比, $\Lambda_{r}$ はモード質量, $p_{r}$ はモード外力, $\phi_{r}$ は 固有振動モードである. 式(2)の運動方程式を周波数 領域に書き換えると, 平板上の点 $\mathbf{x}$ における変位 $W(\mathbf{x}, \omega)$ は, $P_{r}(\omega)$ を $p_{r}(t)$ のフーリエ変換, $j$ を虚 数単位として, 


$$
\begin{aligned}
& W(\mathbf{x}, \omega)=\sum_{r=1}^{\infty}\left(\frac{P_{r}(\omega)}{\Lambda_{r} Z_{r}(\omega)} \phi_{r}(\mathbf{x})\right) \\
& Z_{r}(\omega)=-\omega^{2}+j 2 \zeta_{r} \omega_{r} \omega+\omega_{r}^{2} \\
& P_{r}(\omega)=\int_{-\infty}^{\infty} \int_{A} \phi_{r}(\mathbf{x}) p(\mathbf{x}, t) e^{-j \omega t} d \mathbf{x} d t
\end{aligned}
$$

となる. さらに, $W(\mathbf{x}, \omega)$ のオートパワースペクトル 密度関数 $S_{W}(\mathbf{x}, \omega)$ は,

$$
\begin{aligned}
S_{W}(\mathbf{x}, \omega) & =\lim _{T \rightarrow \infty} \frac{|W(\mathbf{x}, \omega)|^{2}}{T}=\sum_{r=1}^{\infty}\left(\frac{S_{P_{r}}(\omega)}{\Lambda_{r}^{2}\left|Z_{r}(\omega)\right|^{2}} \phi_{r}^{2}(\mathbf{x})\right) \\
& +\sum \sum\left(\frac{S_{P_{r} P_{s}}(\omega)}{\Lambda_{r} \Lambda_{s} Z_{r}(\omega) Z_{s}^{*}(\omega)} \phi_{r}(\mathbf{x}) \phi_{s}(\mathbf{x})\right) \\
& \cong \sum_{r=1}^{\infty}\left(\frac{S_{P_{r}}(\omega)}{\Lambda_{r}^{2}\left|Z_{r}(\omega)\right|^{2}} \phi_{r}^{2}(\mathbf{x})\right)
\end{aligned}
$$

となる.ここで, $T$ を時間として $S_{P_{r}}(\omega)$ は $P_{r}$ のオ一 トパワースペクトル密度関数, $S_{P_{r} P_{s}}(\omega)$ は $P_{r}$ と $P_{s}$ のク ロスパワースペクトル密度関数である. 低次モードで は, モ一ド密度が低く, $r$ 次モード周波数付近では $s$ 次 モード裾の影響が無視できるため,

$1 /\left|Z_{r}(\omega)\right|^{2} \gg 1 /\left|Z_{r}(\omega) Z_{s}^{*}(\omega)\right|$ が成立するので, 最終行の近 似を行った.

3.1 拡散音堨加振時の応答 拡散音場は, 定在 波音場と異なり，統計的な音場であるため，式(8)中の モード外力 $S_{P_{r}}(\omega)$ を求めるために, 特別な取り扱いが 必要となる. 本論文では, Powell (の)導いたジョイント アクセプタンスを用いて， $S_{P_{r}}(\omega)$ を表現する.

ジョイントアクセプタンス $j_{r r}(\omega)$ を用いると, モ 一ド外力 $S_{P_{r}}(\omega)$ は, 次のように書ける.

$$
\begin{gathered}
S_{P_{r}}(\omega)=A^{2} S_{p}(\omega) j_{r r}(\omega) \\
j_{r r}(\omega) \equiv \frac{1}{A^{2}} \int_{A} \int_{A^{\prime}} \phi_{r}(\mathbf{x}) C_{p}\left(\mathbf{x}, \mathbf{x}^{\prime}, \omega\right) \phi_{r}\left(\mathbf{x}^{\prime}\right) d \mathbf{x} d \mathbf{x}^{\prime} \\
C_{p}\left(\mathbf{x}, \mathbf{x}^{\prime}, \omega\right) \equiv S_{p}\left(\mathbf{x}, \mathbf{x}^{\prime}, \omega\right) / S_{p}(\omega)
\end{gathered}
$$

$A$ は平板の面積, $S_{p}\left(\mathbf{x}, \mathbf{x}^{\prime}, \omega\right)$ は平板上の点 $\mathbf{x}$ と $\mathbf{x}^{\prime}$ における音圧のクロスパワースペクトル密度関数で ある. $S_{p}(\omega)$ は, 平板が剛体である場合の拡散音場に お汸る均質な表面音圧（この音圧をブロック音圧と 呼び，遠方音圧の 2 倍である) のオートパワースペク トル密度関数であり，平板振動による放射音圧は無
視している. $C_{p}\left(\mathbf{x}, \mathbf{x}^{\prime}, \omega\right)$ は $S_{p}(\omega)$ により正規化され た正規化クロスパワースペクトル密度関数であり， 本論文で考えるような三次元拡散音場の場合, 次式 で表される゚。

$$
C_{p}\left(\mathbf{x}, \mathbf{x}^{\prime}, \omega\right)=\frac{\sin \left(k_{0}\left|\mathbf{x}^{\prime}-\mathbf{x}\right|\right)}{k_{0}\left|\mathbf{x}^{\prime}-\mathbf{x}\right|}=\operatorname{sinc}\left(k_{0}\left|\mathbf{x}^{\prime}-\mathbf{x}\right|\right)
$$

$k_{0}$ は音場の波数 $\left(k_{0}=\omega / c, c\right.$ : 音速 $)$ である. $\operatorname{sinc}(0)$ は, 同一点相関を表し, 值は 1 である. 式(12)は 2 点 間の距離 $\left|\mathbf{x}^{\prime}-\mathbf{x}\right|$ にのみ依存している.

平板のモード形状が得られれば，式(10)によりジョ イントアクセプタンスが計算出来, 式(9)からモード 外力, 式(8)から平板の応答が求まる.

$3 \cdot 2$ 定在波音場加振時の応答 定在波音場にお ける平板表面の音圧 $p(\mathbf{x}, t)$ が与えられた場合の平板 の応答を考える. 拡散音場加振時の応答が式(8),(9)のよ うにオートパワースペクトル密度関数で得られている ため, 定在波音場加振時の変位応答もオートパワース ペクトル密度関数の形で表現することを考える.

音圧 $p(\mathbf{x}, t)$ を無次元の音圧分布項 $\psi(\mathbf{x})$ と一定振幅 を持つ調和振動項 $P_{0} e^{j \omega_{s} t}$ に分離すると,

$$
p(\mathbf{x}, t)=P_{0} e^{j \omega_{s} t} \psi(\mathbf{x})
$$

となる. $\omega_{s}$ は定在波音場の固有角振動数である.4章 では，「掂散音場のオートパワースペクトル密度関数 と定在波音場の最大音圧のオートパワースペクトル密 度関数が等しいとという条件で平板の応答を比較する ため, $\psi(\mathbf{x})$ は平板内で最大振幅が 1 となるように規格 化している. 式(13)を式(7)に代入し， $S_{P_{r}}\left(\omega_{s}\right)$ を計算す ると，

$$
\begin{aligned}
& S_{P_{r}}\left(\omega_{s}\right)=S_{P_{0}}\left(\omega_{s}\right) \Psi_{r}^{2} \\
& \Psi_{r}=\int_{A} \phi_{r}(\mathbf{x}) \psi(\mathbf{x}) d \mathbf{x}
\end{aligned}
$$

となる. $S_{P_{0}}\left(\omega_{s}\right)$ は, 調和振動項 $P_{0} e^{j \omega_{s} t}$ のオートパワ 一スペクトル密度関数である. 式(14)と式(8)から， $\omega_{s}$ に おける平板の応答が求まる.

次に, 音圧分布項 $\psi(\mathbf{x})$ を検討する. 小金井らが示 したように(4)，フィルエフェクト発生時の定在波音場 は板厚方向に音圧は変化せず, 平板の中心で最も音 圧が大きく, 平板の端部に向けて音圧が減少する固 有音響モードである.また，この音場は，図 1 の Zone Cに示すように, 端部で開口部を有している. 本論文 
では, 音場開口部の境界条件, 即ち, 音響インピー ダンスや狭空間のクリアランス間隔によって異なる あらゆる定在波音場を考慮するため, 音圧分布項 $\psi(\mathbf{x})$ は次式とする.

$$
\psi(\mathbf{x})=\cos \left\{\frac{\alpha \pi\left(x-\frac{L_{x}}{2}\right)}{L_{x}}\right\} \cos \left\{\frac{\beta \pi\left(y-\frac{L_{y}}{2}\right)}{L_{y}}\right\}
$$

式(16)は， $\psi(\mathbf{x})$ の正規化条件を満足している.ここに, $\alpha, \beta$ は, 互いに無相関で, 次式の条件を満たす一様 分布ランダム変数である.

$$
0.5 \leq \alpha \leq 1, \quad 0.5 \leq \beta \leq 1
$$

$\alpha=\beta=1$ の場合, 音場開口部では $\psi(\mathbf{x})=0$, 即ち, 音場開口部が圧力開放境界であり, 現実問題で $\alpha, \beta$ が 1 を超えることは無い,一方， $\alpha=\beta=0$ の場合は, 定在波音場は，場所によらず一定音圧 $\psi(\mathbf{x})=1$ となる. 小金井らの研究によると, クリアランス間隔によって 変化する定在波音場の固有振動数のシフト率は, 最大 でも 30\%であることが分かっている. 周波数は波長と 反比例しており, 式(17)では, 波長変化の下限值を $50 \%$ として， $\alpha, \beta$ の下限值を 0.5 に設定した. 尚, (16)式 において $\alpha, \beta$ に大きな值を与えると，より高次の定 在波音場を考慮出来るが，フィルエフェクトの音圧上 昇が最も顕著で設計上考慮が必要なのは，最低次の定 在波音場であるため, 本論文では, $\alpha, \beta$ は 1 以下とし た.

平板の寸法が $L_{x}=600 \mathrm{~mm}, L_{y}=400 \mathrm{~mm}$ である場 合の音圧分布項 $\psi(\mathbf{x})$ の一例を図 3 に示す.

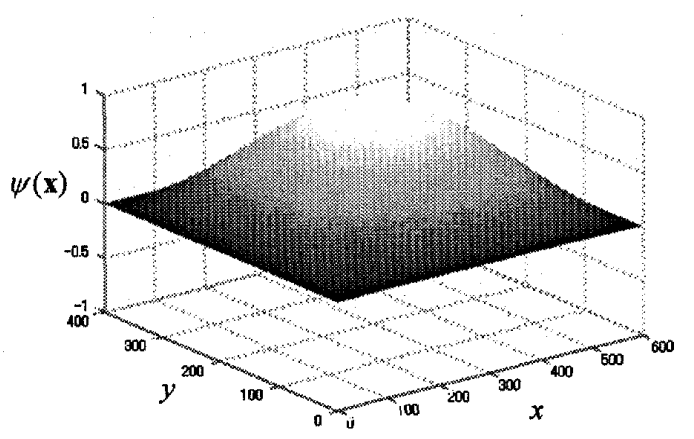

Fig. 3 Sound pressure distribution $\psi(\mathbf{x})(\alpha=\beta=1)$

\section{4. 数値シミュレーション}

$4 \cdot 1$ シミュレーションの手順 3 章で得られた 拡散音場と定在波音場負荷時の平板の応答は, 次式 で表される.

$$
\begin{aligned}
& S_{W}^{D A F}(\mathbf{x}, \omega)=\sum_{r=1}^{\infty}\left(\frac{A^{2} S_{p}(\omega) j_{r r}(\omega)}{\Lambda_{r}^{2}\left|Z_{r}(\omega)\right|^{2}} \phi_{r}^{2}(\mathbf{x})\right) \\
& S_{W}^{S W F F}\left(\mathbf{x}, \omega_{s}\right)=\sum_{r=1}^{\infty}\left(\frac{S_{P_{0}}\left(\omega_{s}\right) \Psi_{r}^{2}}{\Lambda_{r}^{2}\left|Z_{r}(\omega)\right|^{2}} \phi_{r}^{2}(\mathbf{x})\right)
\end{aligned}
$$

$S_{W}^{D A F}$ は拡散音場負荷時の応答, $S_{W}^{S W F}$ は定在波音場負 荷時の忘答である. 式(19)は, 定在波音場の固有角振動 数 $\omega_{s}$ における応答であることに注意する.

本報では，平板の固有振動数が，音響試験の拡散 音場とフィルエフェクトの定在波音場で加振された 場合の応答の違いを検討することを目的としている. もし, 平板の固有振動数が定在波音場の固有振動数. と一致せず十分離れていれば，設計上，フィルエフ エクトによる定在波音場は問題とならない. しかし， 数十 $\mathrm{Hz}$ から $200 \mathrm{~Hz}$ といったフィルエフェクトの顕著 な周波数においては, 宇宙機の構造数学モデルの不 確定性が高いのが現実である. そこで, 現実の設計 においては, 最悪な条件として, 平板の固有振動数 と定在波音場の固有振動数が一致した場合の応答比 較が必要となる.

そこで, 平板の固有振動モード $(r=1,2, \cdots)$ それぞ れについて, 固有振動数を定在波音場の固有振動数 に一致させる.ささらに，拡散音場と定在波音場を同 じ音圧オートパワースペクトル密度で比較するため, $S_{p}\left(\omega_{r}\right)=S_{P_{0}}\left(\omega_{s}\right)$ とする. さらに, 考慮する固有振動 モード以外のモードの影響を無視すると，式(18),(19) から分かるように，拡散音場と定在波音場負荷時の平 板の応答は, 減衰を含む共通項以外の $A^{2} j_{r r}\left(\omega_{s}\right)$ と $\Psi_{r}^{2}$ を比較すればよいことが分かる. 即ち, 平板の振動モ 一ドそれぞれに対して求まる $A^{2} j_{r r}\left(\omega_{s}\right)$ に対して，音 圧分布項 $\Psi_{r}^{2}$ を繰り返し, 総当たりで, 比較を行う.

$4 \cdot 2$ 平板の諸元. シミュレーションを行う平板 の諸元を表 1 に示す. 平板の境界条件は, 四辺単純 支持である. 音響媒体はフェアリング内部と同じ空 気とし, その密度は $1.2 \mathrm{~kg} / \mathrm{m}^{3}$, 音速 $c$ は $340 \mathrm{~m} / \mathrm{sec}$ と する. 
Table 1 Properties of the plate

\begin{tabular}{|c|l|}
\hline Parameter & \multicolumn{1}{|c|}{ Value } \\
\hline Dimension & $L_{x}=600 \mathrm{~mm}, L_{y}=400 \mathrm{~mm}$ \\
\hline Thickness & $h=10 \mathrm{~mm}$ \\
\hline Material & Aluminum \\
\hline Density & $2700 \mathrm{~kg} / \mathrm{m}^{3}$ \\
\hline Young's modulus & $E=70 \mathrm{GPa}$ \\
\hline Poisson ratio & $v=0.3$ \\
\hline
\end{tabular}

4-3 シミュレーション結果４.1節に示した手 順で, $A^{2} j_{r r}\left(\omega_{s}\right)$ と $\Psi_{r}^{2}$ の比較を行った. 定在波音場 の $\Psi_{r}^{2}$ は, 各固有振動モードに対して, ランダム変数 $\alpha, \beta$ を 100 組求め, その組毎に $\Psi_{r}^{2}$ を計算するモンテ カルロシミュレーションを行った．平板の固有角振動 数及び固有振動モードは, 次式に示寸解析解を用いた.

$$
\begin{aligned}
& \omega_{r}=\left.\sqrt{\frac{D}{\mu}}\left\{\left(\frac{m \pi}{L_{x}}\right)^{2}+\left(\frac{n \pi}{L_{y}}\right)^{2}\right\}\right|_{\substack{m=1,2,3, \ldots \\
n=1,2,3, \cdots}} \\
& \phi_{r}(x, y)=\left.\frac{2}{\sqrt{L_{x} L_{y} \mu}} \sin \left(\frac{m \pi x}{L_{x}}\right) \sin \left(\frac{n \pi y}{L_{y}}\right)\right|_{\substack{m=1,2,3, \ldots \\
n=1,2,3, \ldots}}
\end{aligned}
$$

$m, n$ は, 固有振動モード形を決める整数である. シミ ユレーション結果を図 4 に示す．横軸は平板の固有振 動モードのモード次数, 縦軸は $A^{2} j_{r r}\left(\omega_{s}\right)$ と $\Psi_{r}^{2}$ である.

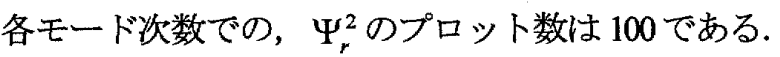
$\Psi_{r}^{2}$ のプロットのないモード次数は, いかなる $\alpha, \beta$ の 值でも, $\Psi_{r}=\int_{A} \phi_{r}(\mathbf{x}) \psi(\mathbf{x}) d \mathbf{x}=0$ となるモードである. 図 4 の結果から, 平板の応答は, 1 次と 20 次を除けば, 殆どの場合，拡散音場の方が大きいことが分かる. 即 ち, 同じ音圧オートパワースペクトル密度の場合, 音 響試験の拡散音場の方がフィルエフェクト発生時の 定在波音場よりも，加振効率が良い，即ち，設計で は安全側であることを示している。

尚，定在波の応答の方が大きい場合の多い 1 次, 20 次の固有振動モードの $m, n$ は, $(m, n)=(1,1),(1,5)$ で ある.これらのモードは，音場と良く連成し，音響放 射効率が高い( ${ }^{(8)}$. 宇宙機構体の平板パネルが，フィル エフェクトの周波数帯域にこのような固有振動モ一 ド形を持つ場合, 設計上注意が必要であることを示 している.すなわち，提案する計算手法によって上 述のように全モードではなく, 設計検討を行う必要 のあるモードを洗い出すことが出来, 現実の宇宙機 設計現場で極めて実用的な手法となる.

次に, 図 4 の $\Psi_{r}^{2}$ の分布について, 統計的な検討を 行う. 各モードにおける $\Psi_{r}^{2}$ の分布について，正規分
布及び対数正規分布の検定を行ったが， $\Psi_{r}^{2}$ は両分布 に従わない結果を示した. そこで, 100 個の $\Psi_{r}^{2}$ の下位 から 95 番目に相当する $\Psi_{r}^{2}$ を求め, $A^{2} j_{r r}\left(\omega_{s}\right)$ と比較 を行った. この結果を図 5 に示寸. 図中のP95 とは, $\Psi_{r}^{2}$ の分布の $95 \%$ を包絡する値を示す.この考え方は, 宇宙機の確率論的な上限值計算でよく用いられる方 法(9)である. 図 5 の結果から，概ね，拡散音場の応答 が定在波音場の 95\%包絡值よりも大きいが，モード によっては拡散音場の応答を上回る場合があること が分かる.

本報では，構造体として平板を扱ったが，提案す る計算方法は，太陽電池パドルやアンテナなど任意 の構造体に対して適用可能である. 任意の構造体の 固有值解析を行い, 固有振動モード形から $A^{2} j_{r r}\left(\omega_{s}\right)$ と $\Psi_{r}^{2}$ を計算し，これらを比較する. フィルエフェク 卜の定在波音場の方が拡散音場よりも応答が大きくな り得るモードを洗い出し, そのモードによる構造強 度・搭載機器の振動環境の詳細検討を行うことが出来 る。

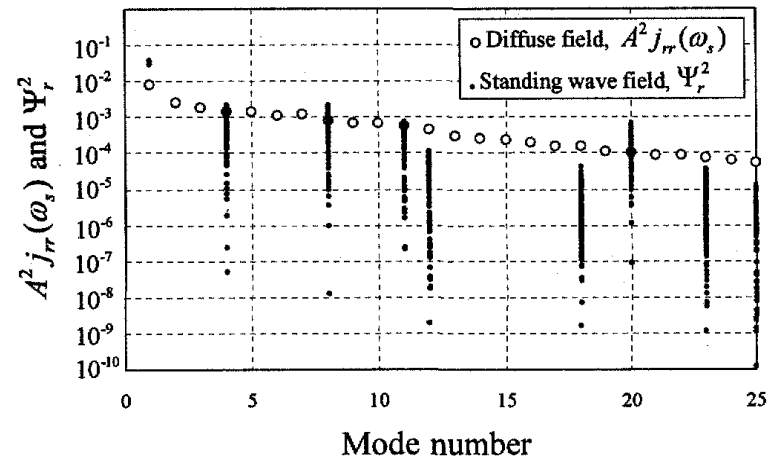

Fig.4 Comparison of the plate responses between diffuse sound field and standing wave field

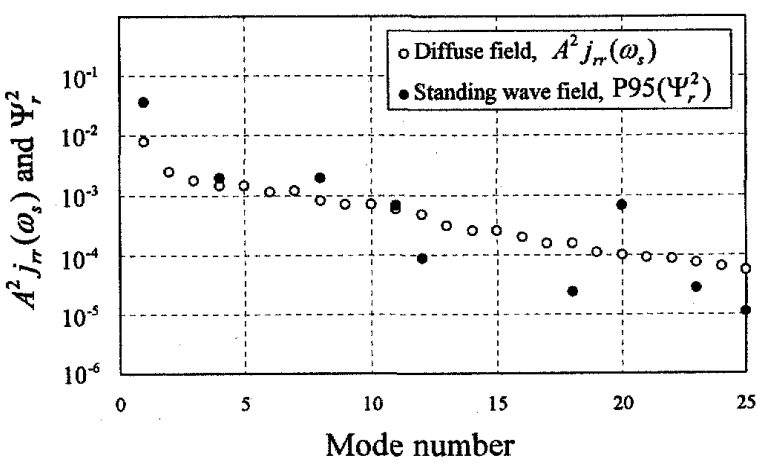

Fig.5 Comparison of the plate responses between diffuse sound field and standing wave field (P95) 


\section{5. 結言}

本報は, 宇宙機打ち上げ時の音圧上昇現象であるフ イルエフェクトによる構造振動応答への影響を簡易 的に検討する手法を提案した．地上での音響試験環 境である拡散音場負荷とフィルエブェクによる定 在波音場負荷における構造振動応答を求める簡易的 な計算式を導いた，定在波音場負荷の場合，音場開 口部のあらゆる境界条件及び間隔を考慮して，モン テカルロシミュレーションを用いて多くの条件下で の解析を行った．研究の成果を以下に纏める。

（a）音場開口部のあらゆる境界条件及び間隔を考慮 して，フィルエフェクトが生成する定在波音場 をモンテカルロシミュレーション定式化する簡 易計算法を提案した。

(b) 拡散音場と定在波音場による構造振動応答の大 小を示す量を明らかにし，これを用いて二つの 音場の加振優位性を解析した。

(c) 殆どの構造モードに対して拡散音場は加振の優 位性を示しているものの， いくつかの構造モー ドに対して，定在波は優位性を示した。これら のモードのモード形状は定在波の音圧分布と概 ね一致していることを確認した。

\section{参考文献}

(1) Y. A. Lee, Payload Fairing Fill Factor Prediction Methodology, NASA CR-189280 (1992).
(2) W. O. Hughes, M. E. McNelis and J. E. Manning, 1994, NASA LeRC's Acoustic Fill Effect Test Program and Results, NASA TM-106688 (1994).

(3) R. Koganei, Q. Shi, S. Ando, I. Hagiwara,The Elucidation Of Mechanism Of Local Sound Pressure Increase Phenomenon, Proceedings of 2004 ASME/JSME Pressure Vessels and Piping Division Conference July 25 -29, 2004 in San Diego, California, USA.

(4) R. Koganei, S. Ando, Q. Shi, I.Hagiwara, "Sound Vibration Analysis at the time of an artificial satellite launch", Transactions of the Japan Society of Mechanical Engineers, Series C, Vol.71, No.708 (2005), pp.2485-2491.

(5) Payload Vibroacoustic Test Criteria, NASA-STD-7005, (1996).

(6) Powell, A., On the Fatigue Failure of Structures due to Vibration Excited by Random Pressure Fields, Journal of the Acoustical Society of America, Vol.30, No12 (1958)., pp1130-1135.

(7) Morrow, C.T., Point-to-point Correlation of Sound Pressures in Reverberation Chambers, Journal of Sound and Vibration, No.16(1) (1971)., pp29-42.

(8) C. E. WALLACE, Radiation Resistance of a Rectangular Panel, The Journal of Acoustical Society of America, Vol.51, No3(part 2) 1972.

(9) Kern, D.L. et al., Dynamic Environmental Criteria, NASA-HDBK-7005, (2001). 